\title{
Metabolic rate at rest and during sleep in a thermoneutral environment
}

\author{
Charmaine Childs
}

\begin{abstract}
This study characterised the pattern of oxygen consumption $\left(\nabla^{\circ}\right)$ in healthy infants and children asleep and awake (at rest) in a thermoneutral environment. Measurement of respiratory gas exchange $\left(\hat{\mathrm{V}}_{2}\right.$ and $\left.\hat{\mathrm{V}}_{2}\right)$ was made using an open circuit flow through system of indirect calorimetry with a specially designed facemask for the collection of exhaled breath. Fifty two healthy subjects aged $\mathbf{4 . 5}$ months to 12.8 years were studied for 15-20 minutes; 18 during sleep and 34 at rest (awake). There was a curvilinear relation between $\mathrm{Vo}_{2}$ and age in the two groups and children aged 2 years or less had the highest values. The value of $\mathrm{VO}_{2}$ was significantly higher in the awake subjects $(12.5-15.0 \mathrm{ml} / \mathrm{min} / \mathrm{kg}$ compared with $7 \cdot 5-9.0$ $\mathrm{ml} / \mathrm{min} / \mathrm{kg}$ in sleeping children). Comparison of the regression lines after $\log$ transformation of these data showed a significant difference in $\mathrm{VO}_{2}$ of resting and sleeping subjects up to the age of 9.5 years.
\end{abstract}

(Arch Dis Child 1993; 68: 658-661)

Recent studies of the metabolic response to burn injury in young children has shown marked fluctuations in oxygen consumption during the acute post-burn period (C Childs, unpublished data). Whether these changes represent a deviation from the normal range is unclear because so little is known about metabolic activity in the healthy young child, particularly under the special environmental conditions in which burn patients are nursed.

It was therefore essential to study a group of healthy children of different ages, exposed to similar conditions as the patients, to act as a control group. Of particular interest were those children under the age of 5 years because this is the age group in which childhood burns and scalds most often occur. ${ }^{1}$ Healthy children were recruited as a control group and were studied either at rest or during sleep in a warm, approximately thermoneutral environment. They were similarly insulated to the patients, with bandages covering $20 \%$ of the body surface, an insulation of about $0.2 \mathrm{clo}^{2}$ and equivalent to a lightly clothed subject.

While providing important data for our studies of patients with burns, the results have also allowed us to characterise metabolic activity in childhood and consequently they may be of interest to others studying metabolic activity in young children.

\section{Subjects and methods}

SUBJECTS

Fifty two healthy children aged 4.5 months to
$12 \cdot 8$ years (median $5 \cdot 1$ years) were divided into two groups. The first group (group A, 34 children; table), aged 5 months to 12.9 years, had bandages applied to about $21 \%$ of their body surface and wore nothing except for nappies or underpants. They were studied at rest in a warm, approximately thermoneutral environment $\left(\mathrm{T}_{\mathrm{a}}=28-33^{\circ} \mathrm{C}\right)$. A second group (group B, 18 children; table) of children aged 4.5 months to 14 years were studied during sleep. Fourteen of the 18 children were studied in a hospital ward on the night before minor elective surgery for non-inflammatory disorders. They were put to bed in nightwear and covered by bedclothes. The ambient temperature was lower $\left(\mathrm{T}_{\mathrm{a}}=23-30^{\circ} \mathrm{C}\left(\right.\right.$ median $\left.23.9^{\circ} \mathrm{C}\right)$ ) than for group A but because they were in bed their immediate environment was comparable with a thermoneutral state and in the range $29-32^{\circ} \mathrm{C}$. The temperature under the bedclothes was measured with a thermocouple suspended inside a hollow cardboard tube placed in the bed.

The other four children were originally recruited for group A (and were thus prepared and bandaged as described for group A) but because they fell asleep during the measurements they were assigned to group B. As a result of the difficulties in measurement of oxygen consumption in young children it was not possible to design the study so that each child was studied awake and then again after falling asleep.

\section{EQUIPMENT}

Before the study began measurements of body temperature (measured in the mouth or axilla) were made and the child's height and weight were recorded. After an initial settling in period measurements of respiratory gas exchange were made using a specially designed open circuit flow through system of indirect calorimetry. A detailed account of the method of construction, principle of operation, assessment, and calibration of the system has been reported elsewhere but a brief description of the method of gas collection is relevant here. Children in groups A and $B$ were prepared for the study as described earlier. Each child was studied only in the company of a parent and in some instances with a sibling (if more than one child from a family had been recruited for the study). A single measurement was taken in each child. Measurements began once it was clear that the child was comfortable, relaxed, and at rest or (for group B subjects) had been asleep for at least two hours. The child's expired gas was collected into a hard, clear, plastic facemask, which was developed for the specific requirements of this study. ${ }^{3}$ The mask was held gently over the nose and mouth to give a close fit around the face. ${ }^{3}$ Ambient air 
Characteristics of the two groups of children studied

\begin{tabular}{|c|c|c|c|c|}
\hline Group & $\begin{array}{l}\text { Age range } \\
\text { (median) }\end{array}$ & $\begin{array}{l}\text { Weight range } \\
(\text { median })(\mathrm{kg})\end{array}$ & $\begin{array}{l}\text { Surface } \\
\text { area range } \\
\text { (median) }\left(m^{2}\right)\end{array}$ & Body coverings \\
\hline & $\begin{array}{l}5 \text { months }-12.9 \\
\text { years }(5.3 \text { years) }\end{array}$ & $\begin{array}{c}7 \cdot 5-42 \cdot 5 \\
(19 \cdot 5)\end{array}$ & $\begin{array}{c}0 \cdot 37-1 \cdot 33 \\
(0.78)\end{array}$ & Bandaged ( $21 \%$ body surface area) \\
\hline$B(n=18)$ sleeping & $\begin{array}{l}4.5 \text { months- } 14 \\
\text { years ( } 3.9 \text { years) }\end{array}$ & $\begin{array}{c}7 \cdot 3-47 \cdot 4 \\
(17)\end{array}$ & $\begin{array}{c}0.36-1 \cdot 41 \\
(0 \cdot 71)\end{array}$ & $\begin{array}{l}\text { Four subjects bandaged ( } 20 \% \text { body surface } \\
\text { area); } 14 \text { subjects in nightwear and covered by } \\
\text { bedclothes }\end{array}$ \\
\hline
\end{tabular}

drawn into the mask via two 'horns' on the upper body of the mask mixed with the child's exhaled breath. The design of the mask ensured that there was no leakage of air and all gas (ambient and expired air) was directed through the system to the gas analysers.

\section{MEASUREMENTS}

After the application of the facemask there was a short period (about five minutes) during which the system was allowed to equilibrate. Once a plateau in the concentration of expired oxygen and carbon dioxide was reached data collection was begun and continued over a period of 15-20 minutes. The mask was then removed. Oxygen consumption $\left(\mathrm{V}_{2}\right)$ and carbon dioxide production $\left(\dot{\mathrm{V}} \mathrm{CO}_{2}\right)$ were calculated from standard equations. ${ }^{4}$ Metabolic rate (MJ/24 hours) was calculated from the respiratory exchange ratio and the energy value of $\mathrm{VO}_{2}$, given in the tables of Lusk. $^{\text {s }}$
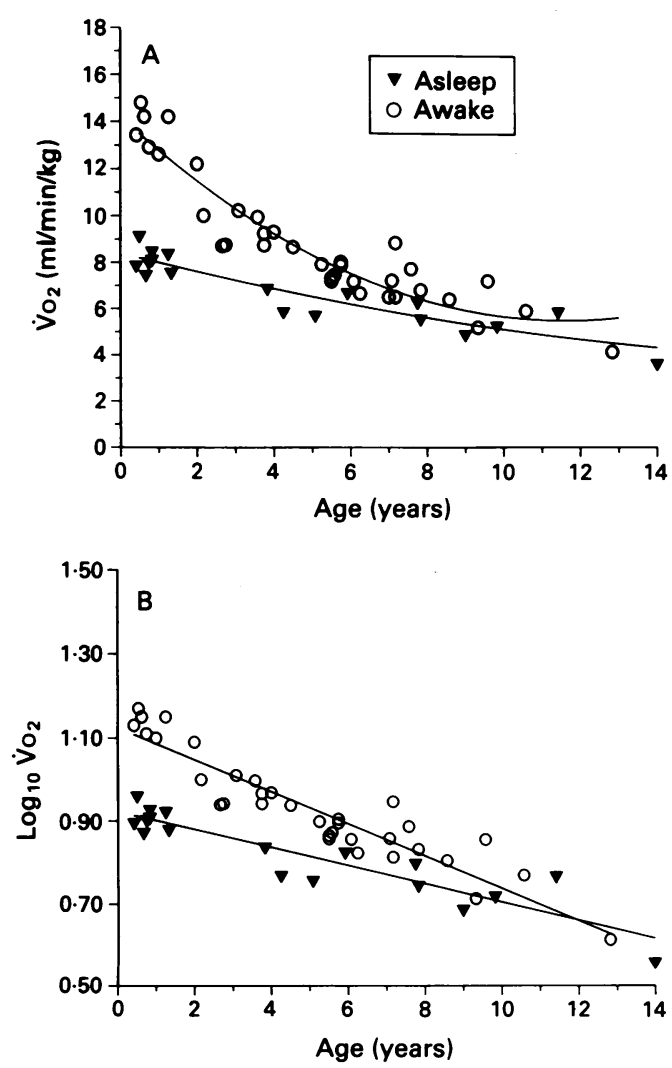

Figure 1 Relation between $\dot{\mathrm{O}}_{2}$ and age in healthy children in a thermoneutral environment. $(A) P$ arabolic regression: asleep, $y=-0.434$ age $+(0.00996 \text { age })^{2}+8.42$ $(r=0.918)$; and resting, $y=-1.514$ age $+(0.06528$ age $)^{2}+14 \cdot 237(r=0.940)$. (B) Linear relation between $\log \dot{V}_{2}$ and age: asleep, $y=-0.022$ age +0.923 $(r=-0.915) ;$ and resting, $y=-0.039$ age +1.125 $(r=-0.931)$.

\section{STATISTICS}

Unless stated otherwise comparisons between groups were made using the Wilcoxon test for unpaired data.

\section{Results}

\section{OXYGEN CONSUMPTION}

Figure 1A shows the measured oxygen consumption $(\mathrm{ml} / \mathrm{min} / \mathrm{kg})$ in 18 sleeping and 34 resting subjects with respect to age. Oxygen consumption in resting children aged 2 years or less was within the range $12.5-15.0 \mathrm{ml} / \mathrm{min} / \mathrm{kg}$ but in sleeping subjects of a similar age $\mathrm{Vo}_{2}$ was significantly lower (about $7 \cdot 5-9.0 \mathrm{ml} / \mathrm{min} / \mathrm{kg}$; $\mathrm{p}<0.01$ ). In the two groups $\dot{\mathrm{Vo}}_{2}$ was highest in the children aged 2 years or less, decreasing with age to reach $4 \cdot 0-5 \cdot 0 \mathrm{ml} / \mathrm{min} / \mathrm{kg}$ at $12-14$ years, values which approximate to oxygen uptake in adults.

The relations between $\dot{\mathrm{V}}_{2}$ and age were curvilinear and best described by a parabolic regression in the resting $(r=0.940)$ and the sleeping $(r=0.918)$ children. Log transformation of these data produced linear relations between $\log \dot{\mathrm{VO}}_{2}$ and age (fig 1B) and comparison of these regression lines showed that the slopes were significantly different $(p<0.001)$ with a significant difference in elevation of the two lines $(\mathrm{p}<0.001)$ up to the age of 9.5 years.

A normal range (mean with $95 \%$ confidence intervals) for $\dot{\mathrm{VO}}_{2}$ at a given age was obtained from the parabolic regression line and is shown for sleeping and resting subjects (fig 2).

\section{RESPIRATORY EXCHANGE RATIO}

The respiratory exchange ratio was calculated from measurements of $\dot{\mathrm{VO}}_{2}$ and $\dot{\mathrm{V}} \mathrm{CO}_{2}$. In sleeping children studied 2-11 hours (median five hours) after food, the respiratory exchange ratio ranged from 0.75 to 0.90 (median 0.81 ). In children studied awake and at rest ( $1 \cdot 5-4 \cdot 0$ hours, median three hours after food) the respiratory exchange ratio was significantly higher at $0.71-1.03$ (median 0.86) $(\mathrm{p}<0.01)$.

\section{METABOLIC RATE}

In sleeping and resting subjects metabolic rate (MJ/24 hour) calculated from measurements of $\dot{\mathrm{Vo}}_{2}$ and $\dot{\mathrm{V}} \mathrm{CO}_{2}$ was compared with the predicted value for basal metabolic rate based on the equations of Schofield ${ }^{6}$ (see appendix).

There was no difference between the regression lines describing the relation between either calculated or predicted metabolic rate and age in the sleeping children (fig 3A). This was not so for the children at rest, however, in whom the measured metabolic rate was higher than pre- 

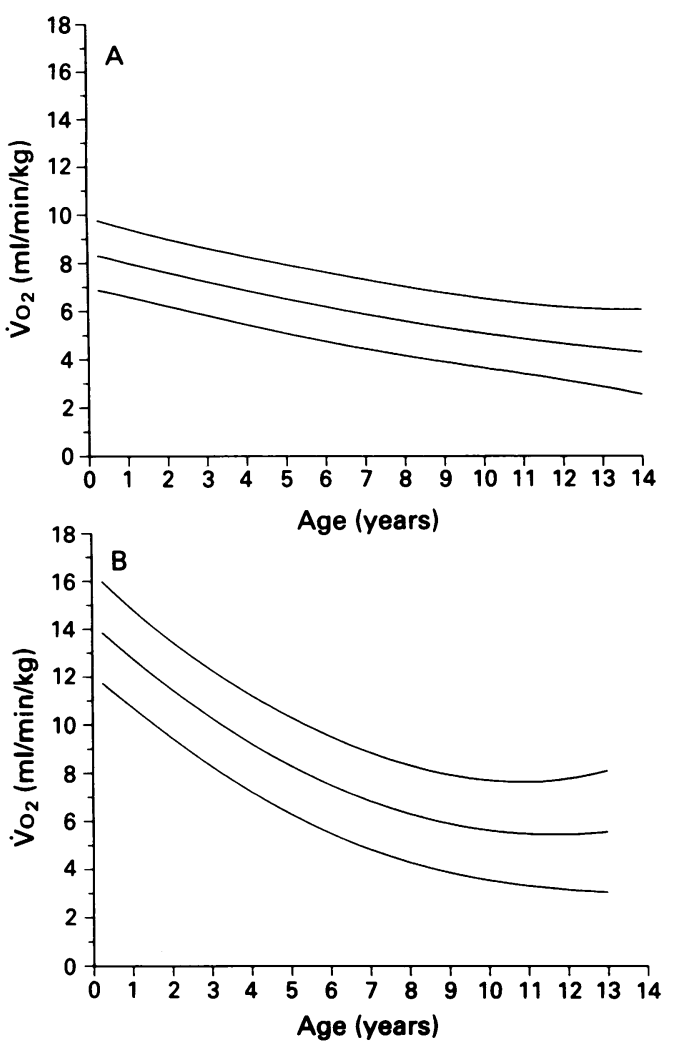

Figure 2 Relation between $\dot{\mathrm{O}}_{2}$ and age in children asleep $(A)$ and resting $(B)$. The lines shown are the parabolic regression (from fig 1) with the 95\% confidence limits.

dicted, the discrepancy being most marked in the youngest children (fig 3B).

\section{Discussion}

The large number of children in this study has allowed us to establish the pattern of oxygen consumption over a wide age range and at
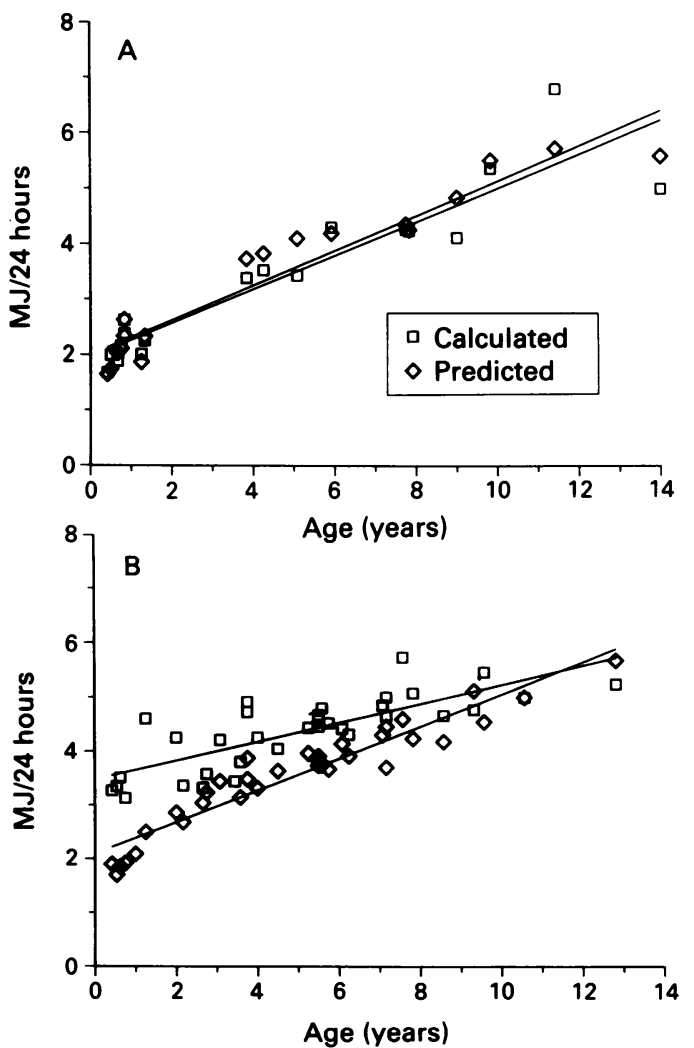

different levels of arousal; awake and at rest as well as during sleep. Oxygen consumption (for each kilogram of body weight) in children at rest was highest in those under the age of 2 years, decreasing towards adult values (about 3-4 m/ $\mathrm{min} / \mathrm{kg}$; L Martineau, personal communication) in older children and teenagers, confirming the pattern reported in adults. ${ }^{7}$ A similar pattern has also been shown in small mammals ${ }^{8}$ where metabolic activity for each kilogram of body weight also decreases after birth but unlike in humans increases in older animals.

Despite some differences in environmental conditions and body coverings all the children in this study were considered to be in an approximately thermoneutral environment at a temperature range falling between the range of thermoneutrality for adults ${ }^{9}$ and the neonate. ${ }^{10}$ For those children exposed to ambient temperatures in the range $28-33^{\circ} \mathrm{C}$, insulation with bandages to about $20 \%$ of the body would not be expected to affect thermoregulation. "For the children studied in bed, measurements of air temperature under the bedclothes showed that almost all of the body was exposed to thermoneutral conditions; the face was generally the only part of the body exposed to a lower air temperature. By studying children at, or close to, thermoneutrality, the influence of environmental factors known to affect metabolic rate can be eliminated.

From measurements of respiratory gas exchange and the respiratory exchange ratio, the metabolic rate was calculated. Owing to the difficulty (and cost) of measuring respiratory gas exchange by indirect calorimetry in sick or injured patients, doctors often refer to nomograms or equations to predict metabolic rate and energy expenditure. Predicting the basal metabolic rate from standard equations is a useful alternative for those who do not have the resources for indirect calorimetry or for those who, having made the measurements, wish to assess whether their own data are comparable with that of others. Schofield assessed the older equations used for the prediction of metabolic rate and concluded that the risk of using inappropriate data in the formulation of equations increases when data is pooled from a large number of sources. ${ }^{6} \mathrm{He}$ then produced a series of equations to calculate the basal metabolic rate in six age groups, from children under the age of 3 years to adults over the age of 60 years.

Although most metabolic studies, particularly in adults, are conducted under basal conditions it is often difficult to subject infants and young children to the same strict requirements. In this study it seemed more appropriate to measure oxygen consumption and carbon dioxide production in a more realistic situation - that is, one which reflects the range of minimal activity during the day. Measurements were therefore made during sleep (which is likely to be a close approximation to the basal metabolic rate) and when children were awake but resting quietly. Only when the healthy children in this study were asleep could metabolic rate be predicted from the equations of Schofield. ${ }^{6}$ We have shown, as have others (B Livingstone, personal communication), that although the sleeping
Figure 3 Relation between calculated and predicted metabolic rate (MF/24 hours) with age in children asleep $(A)$ and at rest $(B)$. 
metabolic rate is commensurate with predicted basal values, rates calculated from measurements of $\dot{\mathrm{VO}}_{2}$ in children who were awake, albeit at rest and in a thermoneutral environment, could not be predicted with accuracy from standard equations of basal metabolic rate.

From observations made during the measurements it was clear that children under the age of about 2 years do not 'relax' or 'rest' as an older child does. There is always some degree of fidgeting, even in the most cooperative of young children. It is this minimal activity which was thought to offer the best explanation for the higher $\dot{\mathrm{VO}}_{2}$ in the resting subjects under the age of 2 years compared with the values for $\mathrm{Vo}_{2}$ in the sleeping children of the same age. The importance of dietary induced thermogenesis should not be overlooked, however. The time interval between the last meal and measurement of $\mathrm{VO}_{2}$ was shorter in the resting than in the sleeping children. Perhaps not surprisingly, therefore, the respiratory exchange ratio tended to be higher in the resting subjects. Thus calculated metabolic rate at a given $\mathrm{VO}_{2}$ will be higher in the resting than in the sleeping children. This effect is insufficient to account for the very marked differences observed in the youngest children, however.

The measurements of $\dot{V}_{2}$ and metabolic rate in sleeping and resting children will help us to interpret the changes in metabolic activity in children with burns during the acute phase after injury.

Thanks are due to Professors R A Little and H B Stoner for their advice during this study. I am grateful to the parents for allowing their children to participate. To the children themselves a sincere thank you; this work would not have been possible without your cooperation. This study was supported by a grant to Dr Childs from the Sir Jules Thorn Charitable Trust.
1 Langley J, Dodge J, Silva PA. Scalds to pre-school children. New Zealand Medical fournal 1981; Feb 11: 84-7.

2 Gagge AP, Nishi Y. Heat exchange between skin surface and thermal environment. In: Lee DHK, ed. Handbook of physiology, section 9. Reactions to environmental agents. Bethesda: American Physiological Society, 1977: 69-92.

3 McGuinness K, Childs C. Development of an indirect calorimeter for use in infants and children. Clin Phys Physiol Meas meter for use in in

4 Murgatroyd PR, Davies HL, Prentice AM. Intra-individual variability and measurement noise in estimates of energy expenditure by whole body indirect calorimetry. $\mathrm{Br} \mathcal{F} N$ utr 1987; 58: 347-56.

5 Lusk G. Animal calorimetry. XXIV. Analysis of the oxidation of mixtures of carbohydrate and fat. A correction. Metabolism 1924; 31: 1234-40.

6 Schofield WN. Predicting metabolic rate, new standards and review of previous work. Human Nutrition: Clinical Nutrition 1985; 39C: 5-95.

7 Harris JA, Benedict FG. A biometric study of basal metabolism in man. Washington: The Carnegie Institute, 1919: 1-266.

8 man. Washington: The Carnegie Institute, 1919: 1-266.

8 Kleiber M. The fre of life. New York: Wiley, 1961, 223-30.

9 Hey E. Thermal neutrality. BrMed Bull 1975; 31: 69-74. productive animals. London: Edward Arnold, 1979.

11 Childs C, Stoner HB, Little RA, Davenport PJ. A comparison of some thermoregulatory responses in healthy children with burn injury. Clin Sci 1989; 77: 425-9.

\section{Appendix}

Equations for predicting basal metabolic rate (BMR; MJ/24 hours) from weight. ${ }^{6}$

\section{Children under 3 years}

Boys: $\quad B M R=0.249$ weight $(\mathrm{kg})-0.127$

Girls: $\quad B M R=0 \cdot 244$ weight $(\mathrm{kg})-0 \cdot 130$

\section{3-10 years}

Boys: $\quad$ BMR $=0.095$ weight $(\mathrm{kg})+2 \cdot 110$

Girls: $\quad B M R=0.085$ weight $(\mathrm{kg})+2.033$

\section{0-18 years}

Boys: $\quad B M R=0.074$ weight $(\mathrm{kg})+2.754$

Girls: $\quad B M R=0.056$ weight $(\mathrm{kg})+2.898$ 